\title{
UNA NUEVA ESPECIE DE MANCOA (BRASSICACEAE) ENDÉMICA DE MICHOACÁN, MÉXICO
}

\author{
Luis Hernández-SANDOVaL ${ }^{1,2}$ y Mahinda MartíneZ \\ ${ }^{1}$ Universidad Autónoma de Querétaro, Licenciatura en Biología, \\ Avenida de las Ciencias s/n, 76230 Juriquilla, Querétaro, México. \\ 22Autor para la correspondencia: luishs@uaq.mx
}

\section{RESUMEN}

Se describe e ilustra Mancoa perennis, una nueva especie endémica al estado de Michoacán, México. Es similar a M. laxa, de la cual difiere en su hábito perenne, los lóbulos de las hojas caulinares ovados a triangulares, enteros, presentando un tricoma ramificado en el ápice y la inflorescencia densa con pedicelos glabros.

Palabras clave: Cruciferae, Mancoa perennis, vulnerable.

\begin{abstract}
Mancoa perennis, a new species endemic to Michoacán, Mexico is described and illustrated. The new species is similar to M. laxa, but differs in its perennial habit, the caulinar leaf lobes ovate or triangular, entire, apically bearing a branched trichome, and a dense inflorescence with glabrous pedicels.
\end{abstract}

Key words: Cruciferae, Mancoa perennis, vulnerable.

El género Mancoa Wedell es un grupo del Nuevo Mundo con ocho especies, hasta antes de esta propuesta. Mancoa es similar a Halimolobos Tausch y a Sphaerocardamum S. Schauer, sin embargo se caracteriza por tener hojas basales y caulinares pinnatisectas o dentadas, a veces pecioladas, frutos angustiseptados con 40 a 100 óvulos, numerosas semillas y funículos generalmente tortuosos, de igual tamaño o más largos que las semillas. Las especies de Mancoa habitan zonas 
planas, valles o cañadas con pastizales húmedos a muy húmedos (Rollins, 1993; Bailey et al., 2007).

En el transcurso del trabajo sobre las crucíferas de Flora del Bajío se detectó un espécimen de Mancoa similar a M. laxa Rollins. Al revisarla con detalle, presentó caracteres únicos diferentes que hacen que se proponga como una especie nueva.

Mancoa perennis L. Hernández \& M. Martínez, sp. nov. Fig. 1.

Similar to Mancoa laxa Rollins, from which it differs in its perennial habit, scarcely branched shoots, caulinar lower leaves non-auriculate, caulinar leaf lobes entire with a branched trichome in the apex, a dense inflorescence with glabrous pedicels, cream color sepals, white petals, and terete filaments.

Planta herbácea perenne por una base leñosa de 10 a $20 \mathrm{~cm}$ de alto; tallo muy ramificado desde la base, creciendo de manera dicotómica en forma de $\mathrm{Y}$, con ramas desiguales en tamaño entre sí y con superficie tuberculada, poco pubescente, con tricomas ramificados sobre un estípite muy corto con 2 a 8 ramas perpendiculares al estípite; hojas basales o de la roseta espatuladas, de ca. $5 \mathrm{~mm}$ de largo, enteras, con tricomas simples en la base y ramificados en el resto de la lámina; hojas caulinares linear-oblongas, de 7 a $10 \mathrm{~mm}$ de largo y 1 a $3 \mathrm{~mm}$ de ancho, ápice agudo, base truncada en las inferiores y auriculada en las superiores, margen someramente lobado, glabras, con 6 a 8 lóbulos; lóbulos ovados a triangulares, enteros, con un tricoma ramificado desde la base en el ápice de cada lóbulo; inflorescencia en forma de racimo alargado, denso, de 5 a $10 \mathrm{~cm}$ de largo, las flores inferiores bracteadas, pedicelos divaricados a ascendentes, rectos, glabros, de 3 a $4 \mathrm{~mm}$ de largo; flores de ca. $3 \mathrm{~mm}$ de diámetro; sépalos de color crema, oblongos a lanceolados, de 1.5 a 1.8 $\mathrm{mm}$ de largo, láminas erectas, margen ondulado; pétalos blancos, espatulados, de $3 \mathrm{a}$ $3.5 \mathrm{~mm}$ de largo y 1 a $1.5 \mathrm{~mm}$ de ancho; estambres 6 , tetradínamos, con nectario en forma de anillo en la base, filamentos rollizos, de 2 a $2.4 \mathrm{~mm}$ de largo, anteras sagitadas, de color amarillo oscuro, de ca. $0.6 \mathrm{~mm}$ de largo; ovario elipsoide, de 1.2 a 1.4 $\mathrm{mm}$ de largo, óvulos 40 a 54, estilo evidente, de 0.8 a $0.9 \mathrm{~mm}$ de largo, con la base cortamente decurrente hacia la línea de sutura, estigma capitado; silicuas oblongas a elipsoides, glabras, ligeramente estipitadas, redondeadas arriba y abajo, comprimidas en sentido contrario al septo, de 2 a $2.5 \mathrm{~mm}$ de largo, de 1 a $1.5 \mathrm{~mm}$ de ancho, valvas redondeadas, con estilos de ca. $1 \mathrm{~mm}$ de largo, fuertemente expandidos en el ápice; semillas (4)8 a 20, cafés, sin alas, rollizas, de 0.3 a $0.5 \mathrm{~mm}$, cotiledones incumbentes, funículos delgados, tortuosos, de 0.5 a $1 \mathrm{~mm}$ de largo. 


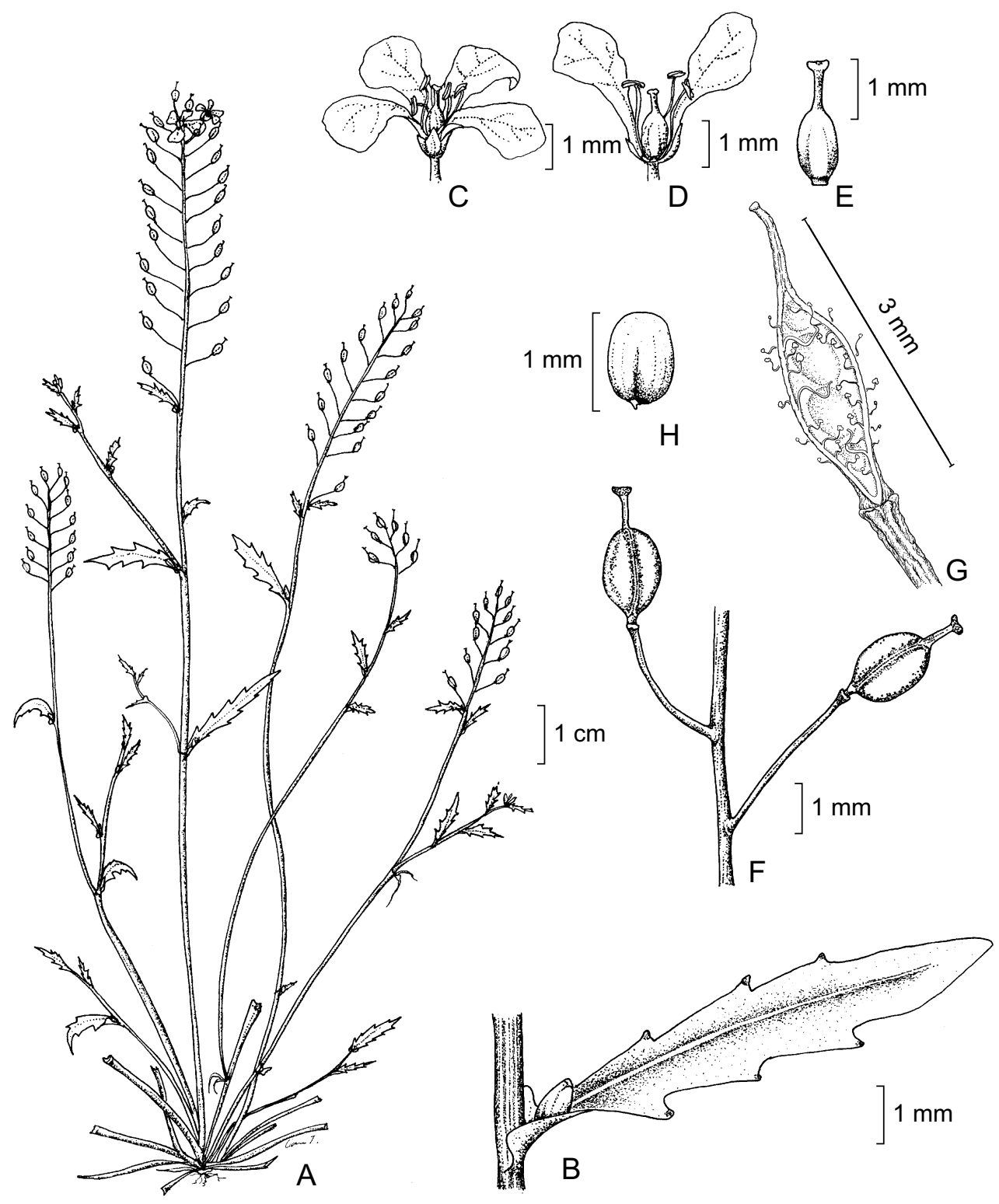

Fig 1. Mancoa perennis sp. nov. A. hábito; B. hoja; C. flor; D. disección de flor; E. ovario; F. porción de infrutescencia; G. porción del fruto mostrando el replum y los funículos tortuosos; los más delgados tienen óvulos abortados; H. semilla. 
Tipo: México, Michoacán, Las Adjuntas, carretera Queréndaro - Maravatío, municipio de Zinapécuaro, H. Díaz B. et al. 6777 (IEB, isotipo QMEX).

Distribución y ecología. Planta rara en bosque de pino-encino, se conoce solo de zonas encharcadas en el norte de Michoacán. Alt. 2100 m.

Fenología: Florece en agosto y fructifica hasta noviembre.

Etimología: El epíteto específico refleja la condición de su hábito.

El nuevo taxon pertenece al grupo de especies con valvas de fruto glabras que presentan Bailey et al. (2007). En particular, es similar a Mancoa laxa, pero se diferencia de ella en varios caracteres de hábito, pubescencia y forma de diferentes estructuras, así como en un tamaño menor de la mayoría de sus órganos (Cuadro 1). Los caracteres diagnósticos de M. laxa son su forma de vida anual con las hojas caulinares auriculadas en la base, lobadas con dientes en los lóbulos, inflorescencias laxas, pedicelos esparcidamente pubescentes, sépalos verdosos, filamentos planos, anteras moradas y silicuas de 5-6 x 2.5-3 $\mathrm{mm}$. Claramente se puede reconocer a $M$. perennis por su hábito perenne, las hojas pequeñas (5-12 x 1-3 $\mathrm{mm}$ ) y la inflorescencia densa. Adicionalmente M. perennis difiere de M. laxa por presentar los lóbulos de las hojas caulinares enteros y con un tricoma ramificado en el ápice, los pedicelos glabros, los sépalos de color crema, los filamentos rollizos, las anteras de color amarillo oscuro y las silicuas de 2-2.5 x 1-1.5 mm. Geográficamente, estas dos especies también se encuentran sumamente separadas, M. laxa en Chihuahua y M. perennis en Michoacán, no habiendo encontrado al momento poblaciones intermedias de ninguna de las dos.

Dado que la nueva especie crece en zonas cercanas a las localidades conocidas de M. bracteata (S. Watson) Rollins, se presentan los caracteres que la diferencian de M. perennis: hábito perenne, hojas basales espatuladas, pequeñas (5-6 x 1.5-2 mm) enteras, hojas caulinares muy escasas, de las cuales las inferiores tienen las bases truncas y las superiores auriculadas, pedicelos divaricados, ascendentes, filamentos rollizos y estilo de $1 \mathrm{~mm}$.

Otra especie endémica de México, de hábito perenne, frutos glabros y viviendo en zonas inundables en el estado de Hidalgo es Mancoa rollinsiana Calderón. Sin embargo, sus hojas basales son pinnatisectas o bipinnatisectas, de $3.5 \mathrm{~cm}$ de largo, pecioladas y las caulinares sésiles de $1.5 \mathrm{~cm}$ de largo, muy diferentes de las de $M$. perennis donde las de la base son enteras de $5 \mathrm{~mm}$ de largo con las caulinares someramente lobuladas de 0.7 a $1 \mathrm{~cm}$ de largo. 
Cuadro 1. Comparación entre las especies cercanas taxonómica o biogeográficamente a la nueva especie de Mancoa.

\begin{tabular}{|c|c|c|c|}
\hline Caracteres & M. laxa & M. perennis & M. bracteata \\
\hline Forma de vida & anual & perenne & anual \\
\hline $\begin{array}{l}\text { Forma de las hojas de la } \\
\text { roseta }\end{array}$ & no observada & espatulada & largamente oblonga \\
\hline $\begin{array}{l}\text { Pubescencia de las hojas de } \\
\text { la roseta }\end{array}$ & no observada & $\begin{array}{l}\text { tricomas simples } \\
\text { en la base, } \\
\text { ramificados en el } \\
\text { resto de la lámina }\end{array}$ & $\begin{array}{l}\text { glabras, a veces con } \\
\text { tricomas ramificados } \\
\text { en el ápice de los } \\
\text { lóbulos de hojas }\end{array}$ \\
\hline $\begin{array}{l}\text { Tamaño de las hojas de la } \\
\text { roseta }\end{array}$ & no observadas & $5-6 \times 1.5-2 \mathrm{~mm}$ & $25-55 \times 5-9 \mathrm{~mm}$ \\
\hline Pecíolos de todas las hojas & no observados & ausentes & presentes \\
\hline Hojas caulinares & escasas & muy escasas & abundantes \\
\hline $\begin{array}{l}\text { Tamaño de las hojas } \\
\text { caulinares }\end{array}$ & $8-12 \times 2-5 \mathrm{~mm}$ & $5-12 \times 1-3 \mathrm{~mm}$ & $15-40 \times 10 \mathrm{~mm}$ \\
\hline $\begin{array}{l}\text { Ápice de los lóbulos de las } \\
\text { hojas }\end{array}$ & redondeado & agudo & agudo a obtuso \\
\hline Pubescencia de las hojas & glabras & $\begin{array}{l}\text { glabras, con un } \\
\text { tricoma ramificado } \\
\text { en cada lóbulo }\end{array}$ & $\begin{array}{l}\text { en las venas } \\
\text { centrales, con 1-5 } \\
\text { tricomas ramificados } \\
\text { o simples en cada } \\
\text { lóbulo }\end{array}$ \\
\hline $\begin{array}{l}\text { Forma de la base de hojas } \\
\text { caulinares }\end{array}$ & auriculada & $\begin{array}{l}\text { las inferiores } \\
\text { truncadas, las } \\
\text { superiores } \\
\text { auriculadas }\end{array}$ & $\begin{array}{l}\text { fuertemente } \\
\text { auriculadas }\end{array}$ \\
\hline Tamaño de las inflorescencias & $10-15 \mathrm{~cm}$ & $5-10 \mathrm{~cm}$ & $2.5-7.5 \mathrm{~cm}$ \\
\hline Brácteas florales & $10 \mathrm{~mm}$ & $2-5 \mathrm{~mm}$ & $10-20 \mathrm{~mm}$ \\
\hline Pedicelos & $\begin{array}{l}\text { esparcidamente } \\
\text { pubescentes }\end{array}$ & glabros & $\begin{array}{l}\text { glabros a } \\
\text { esparcidamente } \\
\text { pubescentes }\end{array}$ \\
\hline Dirección de los pedicelos & $\begin{array}{l}\text { divaricados } \\
\text { ascendentes }\end{array}$ & $\begin{array}{l}\text { divaricados } \\
\text { ascendentes }\end{array}$ & $\begin{array}{l}\text { divaricados en } \\
\text { ángulo recto }\end{array}$ \\
\hline Tamaño de los pedicelos & 3-4 mm de largo & $2-4 \mathrm{~mm}$ & $5-8 \mathrm{~mm}$ \\
\hline Color de los sépalos & verde-amarillento & crema & blanco a crema \\
\hline Filamentos & aplanados & rollizos & aplanados \\
\hline Anteras & moradas & amarillo oscuras & amarillo oscuras \\
\hline Silicuas & $5-6 \times 2.5-3 \mathrm{~mm}$ & $2-2.5 \times 1-1.5 \mathrm{~mm}$ & $3-4 \times 1.5-2 \mathrm{~mm}$ \\
\hline Semillas & $0.75 \mathrm{~mm}$ & $0.5 \mathrm{~mm}$ & ca. $1 \mathrm{~mm}$ \\
\hline
\end{tabular}


Mancoa perennis sólo se ha encontrado en la localidad tipo. Se han llevado a cabo exploraciones adicionales y no ha sido posible ampliar su distribución por lo que se presupone como endémica de Michoacán, México. Es un elemento escaso y puede considerarse vulnerable a la extinción.

\section{AGRADECIMIENTOS}

Agradecemos al Dr. Jerzy Rzedowski la revisión crítica del manuscrito, así como sus acertados comentarios. Clara Tinoco elaboró la ilustración.

\section{LITERATURA CITADA}

Bailey, C. D., I. Al-Shehbaz y G. Rajanikanth. 2007. Generic limits in tribe Halimolobeae and description of the new genus Exhalimolobos (Brassicaceae). Syst. Bot. 32(1): 140-156.

Rollins, R. 1993. The Cruciferae of continental North America. Systematics of the mustard family from Arctic to Panama. Standford University Press. Standford, USA. 976 pp. 